\title{
ANALISIS PERHITUNGAN DAN PEMOTONGAN PPh PASAL 21 KARYAWAN TETAP PADA PT. TELAGA BAKTI PERSADA TERNATE
}

\author{
Linath Masrinah $^{1}$, Jantje. J. Tinangon ${ }^{2}$, Natalia Y.T. Gerungai ${ }^{3}$ \\ ${ }^{1,2,3}$ Fakultas Ekonomi Dan Bisnis. Jurusan Akuntansi Universitas Sam Ratulangi Manado, J1. Kampus Bahu, \\ Manado, 95115, Indonesia \\ E-mail : linathm@yahoo.co.id
}

\begin{abstract}
Taxes are an important component for the government in carrying out state activities in Indonesia, since the financing of routine expenditures as well as government development is largely derived from the tax sector. as it is known that tax revenue plays a vital role since the revenue from the oil and gas sector has decreased. The government in this case the Directorate General of Tax (DJP) always wanted to perform the task in terms of collecting tax revenue so that the nation's survival is maintained. Therefore, the Directorate General of Tax (DJP) is trying to get the tax collection in Indonesia on target by always trying to improve the service by updating the rules of tax collection that meet the requirements of justice, juridical, economic, financial and simple. This study aims to analyze the calculation and withholding of Article 21 Income Tax on the salary of PT. Telaga Bakti Persada Ternate whether it is in compliance with the provisions of the Taxation Law. No. 36 of 2008 Income Tax Income. This research uses Descriptive Research Method. The results of the research can be concluded that the calculation and withholding of income tax article 21 Income Tax on permanent employees of PT. Telaga Bakti Persada Ternate has done calculations and deductions in accordance with the provisions of the current law.
\end{abstract}

Keywords: calculation and deduction of income tax PPh article 21, income tax, receipt income tax PPh article 21, accounting, income tax article 21, Tax Regulation.

\section{PENDAHULUAN}

Pajak merupakan bagian terpenting pemerintah dalam menjalankan roda pemerintahan di Indonesia, karena pembiayaan dan pengeluaran pembagunan negara sebagian besar berasal dari sektor pajak. Dalam usaha meminimalkan pemasukan dari sektor pajak. Pemerintah terus melakukan perbaikan, penyesuaian, dan perubahan pada undang-undang perpajakan yang berlaku pada pajak penghasilan yang mengalami beberapa kali perubahan yakni tiga kali perubahan. Terakhir telah dilakukan perubahan atas Undang-Undang No. 17 Tahun 2000 menjadi Undang-Undang No. 36 Tahun 2008 tentang Pajak Penghasilan. Setiap warga negara yang berkerja pasti akan mendapatkan gaji. Begitu juga dengan orang yang berkerja di perusahaan, akan mendapatkan penghasilan yang diberikan setiap bulannya. Oleh karena itu penghasilan/gaji yang diterima oleh karyawan, pihak pemerintah akan memotong pajak dari setiap penghasilan karyawan yang bekerja. Penelitian ini memiliki tujuan untuk menganalisis perhitungan dan pemotongan $\mathrm{PPh}$ Pasal 21 pada karyawan tetap pada PT. Telaga Bakti Persada Ternate telah sesuai dengan UU yang berlaku saat ini.

\section{TINJAUAN PUSTAKA}

Pengertian Akuntansi. Menurut Hans Kartikahadi, dkk. (2016:3) : “Akuntansi adalah suatu sistem informasi keuangan, yang bertujuan untuk menghasilkan dan melaporkan informasi yang relevan bagi berbagai pihak yang berkepentingan". Pengertian akuntansi menurut Wild \& Kwok (2011:7) dalam Agoes dan Estralita (2013:1) "Akuntansi adalah sistem informasi yang menghasilkan laporan kepada pihak-pihak yang berkepentingan 
mengenai aktivitas ekonomi dan kondisi perusahaan". Menurut situs wikipedia, akuntansi adalah "pengukuran, penjabaran, atau pemberian kepastian mengenai informasi yang akan membantu manajer, investor, otoritas pajak, dan pembuat keputusan lain untuk membuat alokasi sumber daya keputusan didalam perusahaan, organisasi, dan lembaga pemerintahan. Akuntansi adalah seni dalam mengukur, berkomunikasi, serta menginterpretasikan aktivitas keuangan". Dari definisi akuntansi di atas, menurut penulis dapat disimpulkan bahwa "akuntansi adalah suatu proses mengolah data keuangan agar menghasilkan informasi keuangan dalam bentuk laporan keuangan yang kemudiann diberitakan kepada pihak yang berkepentingan seperti organisasi perusahaan ekonmi yang bersanggkutan".

Bentuk Laporan Keuangan. Menurut Kasmir (2012:7) "laporan keuangan adalah laporan yang menunjukkan kondisi keuangan perusahaan pada saat ini atau dalam suatu periode tertentu".

Akuntansi Perpajakan. Pengertian akuntansi pajak menurut Agoes dan Estralita (2013:10) adalah "akuntansi perpajakan adalah menetapkan besarnya pajak terutang berdasarkan laporan keuangan yang disusun oleh perusahaan. Akuntansi perpajakan, merupakan bagian dalam akuntansi yang timbul dari unsur spesialisasi yang menurut keahlian dalam bidang tertentu. Akuntansi perpajakan tercipta karena adanya suatu prinsip dasar yang diatur dalam UU perpajakan dan pembentukannya terpengaruh oleh fungsi perpajakan dalam mengimplementasikan sebagai kebijakan pemerintah".

Pengertian Pajak. Menurut UU No. 36 Tahun 2008 "Pajak adalah kontribusi wajib kepada negara yang terutang oleh orang pribadi atau badan yang bersifat memaksa berdasarkan Undang-Undang, dengan tidak mendapatkan imbalan secara langsung dan digunakan untuk keperluan negara bagi sebesar-besarnya untuk kemakmuran rakyat". Menurut Adriani, yang dikutip oleh Waluyo (2013:2) "Pajak adalah iuran masyarakat kepada negara (yang dapat dipaksakan) yang terutang oleh yang wajib membayaranya menurut peraturan-peraturan umum (undang-undang) dengan tidak mendapat prestasi kembali yang langsung dapat ditunjuk dan yang gunanya adalah untuk membiayai pengeluaran-pengeluaran umum berhubung tugas negara untuk menyelenggarakan pemerintah”. Menurut Harnanto (2013:1) "menyatakan bahwa Pajak adalah pembayaran atau pembebanan yang tidak secara langsung berhubungan dengan barang/jasa yang berada dalam wilayah atau dalam jangkauan pemerintah". Menurut Mardiasmo (2015:8) "Pajak adalah iuran rakyat kepada kas negara berdasarkan undang-undang (yang dapat dipaksakan) dengan tiada mendapat jasa timbal (kontraprestasi) yang langsung dapat ditunjukan dan yang dingunakan untuk membayar pengeluaran umum". Menurut Rochmat Soemitro SH, (Mardiasmo, 2011:6) "Pajak adalah iuran rakyat kepada kas negara berdasarkan undang-undang (yang dapat dipaksakan) dengan tidak mendapat jasa timbal (kontra prestasi) yang lansung dapat ditunjuk dan yang dan yang dingunakan untuk membayar pengeluaran umum".

Pengertian Pajak Penghasilan Pasal 21. Pajak Penghasilan (PPh) Pasal 21 berdasarkan peraturan Direktorat Jendral Pajak No. PER-32/PJ/2015 "adalah pajak atas penghasilan berupa gaji, upah, honorarium, tunjangan dan pembayaran lain dengan nama dan dalam bentuk apapun sehubungan dengan pekerjaan atau jabatan, jasa, dan kegiatan yang dilakukan oleh orang pribadi subjek pajak dalam negeri”.

Wajib Pajak PPh Pasal 21. Penghasilan yang dikenakan atas PPh Pasal 21 adalah : (1) pegawai; (2) pensiunan; (3) bukan pegawai; dan (4) anggota dewan komisaris, mantan pegawai.

\section{Penerima Penghasilan Yang Tidak Dipotong PPh Pasal 21}

1. Pejabat perwakilan diplomatik dan konsultan atau pejabat lain dari negara lain/asing, yang bertempat tinggal di Indonesia.

2. Penerima penghasilan tapi Bukan WNI, dan tidak menerima penghasialan lain. 
Penghasilan Kena Pajak (PKP). Penghasilan Kena Pajak (PKP) merupakan perhitungan awal dalam menentukan besarnya Pajak Penghasilan yang terutang oleh Wajib Pajak (WP). Untuk menetapkan besarnya (PKP), yakni penghasilan Neto dikurangi PTKP. bila penghasilan Neto lebih rendah dari pada (PKP) pajak tersebut terbilang tidak ada atau 0 .

Penghasilan Tidak Kena Pajak (PTKP). PTKP adalah penghasilan bruto Wajib Pajak (WP) atau perseorangan sebagai proses menghitung dan memotong PKP yang menjadi objek pajak penghasilan yang harus bayar oleh wajib pajak. Tarif PTKP terbaru selama setahun untuk perhitungan dan memotong PPh Pasal 21 untuk wajib pajak berdasarkan PMK No. 101/PMK.010/2016 adalah:

\begin{tabular}{ll}
\hline \multicolumn{1}{c}{ Tarif PTKP } & Tarif \\
\hline Untuk diri (WP) orang pribadi & Rp. 54.000.000 \\
Tambahan untuk (WP) kawin & Rp. 4.500 .000 \\
& Rp. 54.000 .000 \\
Untuk istri yang penghasilannya digabung dengan penghasilan suami & Rp. 4.500 .000 \\
$\begin{array}{l}\text { Tambahan untuk setiap anggota keluarga sedarah dan keluarga dalam } \\
\text { garis keturunan lurus serta anak angkat yang mejadi tanggunan }\end{array}$ & \\
sepenuhnya, paling banyak 3 orang untuk setiap keluarga WP & \\
\hline Sumber:PMK Nomor: 101/PMK.010/2016 &
\end{tabular}

PTKP berdasarkan Peraturan Menteri Keuangan Nomor: 101/PMK.010/2016 tersebut

1. Penghasilan tidak kena pajak (PTKP) Wajib Pajak Tidak Kawin

\begin{tabular}{lcll}
\hline \multicolumn{1}{c}{ Deskripsi } & $\begin{array}{c}\text { Status } \\
\text { kawin }\end{array}$ & Nilai & Jumlah \\
\hline Wajib Pajak & (WP) & Rp. 54.000.000,- & Rp. 54.000.000,- \\
Tambah Tangungan 1/anak 1 & $($ TK/1) & Rp. 4.500.000,- & Rp. 58.500.000,- \\
Tambahh Tangungan 2/anak 2 & $($ TK/2) & Rp. 9.000.000,- & Rp. 63.000.000,- \\
Tambahh Tangungan 3/anak 3 & $($ TK/3) & Rp. 13.500.000,- & Rp. 67.500.000,- \\
\hline
\end{tabular}

Sumber : PMK Nomor: 101/PMK.010/2016

2. Penghasilan tidak kena pajak (PTKP) WP Kawin

\begin{tabular}{lcll}
\hline \multicolumn{1}{c}{ Deskripsi } & $\begin{array}{l}\text { Status } \\
\text { kawin }\end{array}$ & Nilai & Jumlah \\
\hline Wajib Pajak & $(\mathrm{WP})$ & Rp. 54.000.000,- & Rp. 54.000.000,- \\
WP Kawin & $(\mathrm{K} / 0)$ & Rp. 4.500.000,- & Rp. 58.500.000,- \\
Tangungan 1/anak 1 & $(\mathrm{K} / 1)$ & Rp. 4.500.000,- & Rp. 63.000.000,- \\
Tangungann 2/anak 2 & $(\mathrm{K} / 2)$ & Rp. 9.000.000,- & Rp. 67.500.000,- \\
Tangungan 3/anak 3 & $(\mathrm{K} / 3)$ & Rp. 13.500.000,- & Rp. 72.000.000,- \\
\hline
\end{tabular}

Sumber : PMK Nomor: 101/PMK.010/2016

3. WP Kawin tambah Penghasilan Istri dan Suami Digabungkan

\begin{tabular}{lclr}
\hline \multicolumn{1}{c}{ Deskripsi } & Status kawin & Nilai & Jumlah \\
\hline Wajib Pajak & $(\mathrm{WP})$ & Rp. 54.000.000,- & Rp. 54.000.000,- \\
Penghasilan gabung & & Rp. 54.000.000,- & Rp. 108.000.000,- \\
WP( Wajib pajak ) Kawin & $(\mathrm{K} / \mathrm{I} / 0)$ & Rp. 4.500.000,- & Rp. 112.500.000,- \\
Ditambah Tangungan 1 & $(\mathrm{K} / \mathrm{I} / \mathrm{1})$ & Rp. 4.500.000,- & Rp. 117.000.000,- \\
Ditambah Tangungan 2 & $(\mathrm{K} / \mathrm{I} / 2)$ & Rp. 9.000.000,- & Rp. 121.500.000,- \\
Ditambah Tangungan 3 & $(\mathrm{K} / \mathrm{I} / 3)$ & Rp. 13.500.000,- & Rp. 126.000.000,- \\
\hline Sumber: "PMK Nomor: 101/PMK.010/2016" & & \\
\hline
\end{tabular}


Tarif PPh yang ditetapkan Atas PTKP

\begin{tabular}{llc}
\hline No. & \multicolumn{1}{c}{ Gaji } & Tarif PPh \\
\hline 1. & Penghasilan/gaji Sampai Rp. 50.000.000 & $(5 \%)$ \\
2. & Penghasilan/gaji Sampai & $(15 \%)$ \\
3. & $\begin{array}{l}\text { Penghasilan/gaji Sampai Rp. 250.000.000 sampai dengan } \\
\text { Rp 500.000.000 }\end{array}$ & $(25 \%)$ \\
4. & Penghasilan/gaji Sampai Rp. 500.000.000 & $(30 \%)$ \\
\hline
\end{tabular}

Sumber : Undang-Uundang No. 36 Tahun 2008 Tentang Pajak Penghasilan (PPh)

Unsur pemotongan penghasilan bruto bagi pegawai tetap :

1. Biaya jabatan bagi pegawai tetap. Biaya jabatan ini telah diatur dalam Pasal 21 ayat (3) Undang-Undang Pajak Penghasilan. Menurut Direktorat Jenderal Pajak Kementerian Keuangan, besaran biaya jabatan adalah sebesar 5\% dari penghasilan bruto setahun. Dengan pengurangan setinggi-tingginya sebesar Rp. 500.000 sebulan atau Rp. 6.000 .000 setahun.

2. Uang pensiun ditanggung sendiri oleh pegawai tetap. Ketentuan Pasal 41 ayat (8) dan Pasal 42 ayat (2) UU Nomor 40 Tahun 2004 tentang Sistem Jaminan Sosial Nasional, Pemerintah Menetapkan : peraturan pemerintah tentang penyelenggaraan program jaminan pensiun dalam Pasal 28.

3. Setor untuk Jaminan Pensiun wajib dibayarkan setiap bulan.

4. Uang yang harus di setor (Iuran) dimaksud pada ayat (1) sebesar 3\% (tiga persen) dari perbulan.

5. Setor (Iuran) sebesar 3\% (tiga persen) sebagaimana dimaksud pada ayat (2) wajib ditanggung bersama oleh Pemberi Kerja selain penyelenggara negara dan Peserta dengan ketentuan: a. 2\% (dua persen) dari upah ditanggung oleh Pemberi Kerja selain penyelenggara negara; dan b. $1 \%$ (satu persen) dari upah ditanggung oleh karyawan.

\section{Penelitian Terdahulu}

\begin{tabular}{|c|c|c|c|c|c|}
\hline $\begin{array}{c}\text { Nama } \\
\text { (Tahun) }\end{array}$ & Judul & $\begin{array}{c}\text { Metode } \\
\text { Penelitian }\end{array}$ & $\begin{array}{c}\text { Hasil } \\
\text { Penelitian }\end{array}$ & $\begin{array}{c}\text { Persamaan } \\
\text { Penelitian }\end{array}$ & $\begin{array}{c}\text { Perbedaan } \\
\text { Penelitian }\end{array}$ \\
\hline $\begin{array}{ll}\text { Jeane } & \text { Susan } \\
(2013) & \end{array}$ & $\begin{array}{l}\text { Analisis } \\
\text { Perhitungan } \\
\text { Pajak } \\
\text { Pengahasilan } \\
\text { Pasal } 21 \text { Pada } \\
\text { PT. } \\
\text { Megasurya } \\
\text { Nusalestari } \\
\text { Manado }\end{array}$ & Deskriptif & $\begin{array}{l}\text { PT. Mega surya } \\
\text { Nusalestari dalam } \\
\text { melakukan } \\
\text { perhitungan Pasal } 21 \\
\text { sudah sesuai degan } \\
\text { Undang-Undang } \\
\text { Pajak Penghasilan }\end{array}$ & $\begin{array}{l}\text { Persamaan penelitian } \\
\text { ini yakni mencoba } \\
\text { membandingkan } \\
\text { perhitungan ran } \\
\text { pemotongan pajak } \\
\text { penghasilan apakah } \\
\text { sudah sesuai dengan } \\
\text { peraturan perundang- } \\
\text { undagan yang ada saat } \\
\text { ini. }\end{array}$ & $\begin{array}{l}\text { Perbedaan } \\
\text { dari penelitian } \\
\text { ini adalah dari } \\
\text { objek/tempat } \\
\text { dilaksanakan } \\
\text { penelitian }\end{array}$ \\
\hline $\begin{array}{l}\text { Anglia Friska } \\
\text { Makabimbang } \\
\text { (2013) }\end{array}$ & $\begin{array}{l}\text { Analisis } \\
\text { Perhitungan, } \\
\text { Pembayaran } \\
\text { dan Pelaporan } \\
\text { Pph Pasal } 21 \\
\text { Pada Dinas } \\
\text { Pedidikan } \\
\text { Kecamatan } \\
\text { Tuminting }\end{array}$ & Deskriptif & $\begin{array}{lr}\text { Dinas pendidikan } \\
\text { kecamatan } & \text { tuminting } \\
\text { dalam perhitungan } \\
\text { Pasal 21 } & \text { sudah sesuai } \\
\text { degan } & \text { Undang- } \\
\text { Undang } & \text { Pajak } \\
\text { Penghasilan. }\end{array}$ & $\begin{array}{l}\text { Persamaan penelitian } \\
\text { ini yakni mencoba } \\
\text { membandingkan } \\
\text { perhitungan dan } \\
\text { pemotongan pajak } \\
\text { penghasilan apakah } \\
\text { sudah sesuai dengan } \\
\text { peraturan perundang- } \\
\text { undagan yang ada saat } \\
\text { ini. }\end{array}$ & $\begin{array}{l}\text { Perbedaan } \\
\text { dari penelitian } \\
\text { ini adalah dari } \\
\text { objek/tempat } \\
\text { dilaksanakan } \\
\text { penelitian. }\end{array}$ \\
\hline
\end{tabular}




\section{METODE PENELITIAN}

Jenis Penelitian. Jenis penelitian yang dilakukan ini adalah penelitian deskriptif kualitatif. data kualitatatif adalah data yang di sajikan dalam betuk uraian.

Tempat Dilaksanakan Penelitian dan Waktu Penelitian di laksanakan. penelitian ini dilaksanakan di PT. Telaga Bakti Persada Ternate. Waktu penelitian ini dilaksanakan adalah selama 2 bulan dari bulan April sampai Mei Tahun 2018.

Objek Penelitian. Dalam penelitian ini yang menjadi objek penelitian adalah Perhitungan dan Pemotongan PPh Pasal 21 atas penghasilan karyawan PT. Telaga Bakti Persada Ternate.

Sumber Data Penelitian. Dalam penelitian ini Sumber data yang digunakan yakni data primer data penelitian didapat langsung dari PT. Telaga Bakti Persada Ternate. penelitian ini mengunakan data primer data yang digabungkan, dan diolah langsung di PT. Telaga Bakti Persada Ternate, yaitu berupa daftar gaji.

Metode Pengumpulan Data. Pengumpualan data dalam penelitian ini adalah metode kualitatif, yakni sebagai berikut: (1) proses tanya jawab; (2) observasi; dan (3) studi dokumen.

Metode Analisis. Penelitian ini mengunakan metode deskriptif. Dengan menggunakan metode ini penulis dapat mengetahui perhitungan dan pemotongan $\mathrm{PPh}$ Pasal 21 pada karyawan tetap pada PT. Telaga Bakti Persada Ternate apakah telah sesuai dengan ketentuan undang-undang yang berlaku saat ini yakni UU No. 36 Tahun 2008 tentang Pajak Penghasilan (PPh).

Proses Analisis. Teknik analisis data dalam penelitian ini adalah sebagai berikut:

1. Mengumpulkan dan mempelajari dokumen-dokumen berupa daftar gaji bulan JanuariDesember 2017 dan dokumen penunjang yang berhubungan dengan judul penelitian.

2. Menganalisis perhitungan dan pemotongan WP terhadap gaji karyawan PT. Telaga Bakti Persada Ternate.

3. Memperoleh gambaran umum perusahaan secara keseluruhan serta mengetahui permasalahanyang akan diteliti.

4. Mengolah, membandigkan hitungan dan pemotongan PPh Karyawan yang dilakukan perusahaan terlah sesuai atau tidak dengan UU Perpajakan yang berlaku saat ini.

5. Menarik kesimpulan dan memberikan saran pada perusahaan.

\section{HASIL ANALISIS DAN PEMBAHASAN}

\subsection{Gambaran Umum Perusahaan}

PT. Telaga Bakti Persada Ternate merupakan salah satu perusahaan yang bergerak dalam bidang usaha pemanfaatan hasil hutan kayu yang berlokasi di Provinsi Maluku Utara yang berada di kecamatan Obi kabupaten Halmahera Selatan, perusahaan ini mulai beroperasi dari Tahun 1989.

Perhitungan dan Pemotongan PPh Pasal 21. PPh Pasal 21 karyawan PT. Telaga Bakti Persada Ternate, diperoleh dari gaji bulanan di tambah tunjangan-tunjangan berupa tunjangan makan, tunjangan transportasi dan tunjangan kesehatan bagi karyawan. Penghasilan Neto kemudian disetahunkan dan akan dikurangi dengan (PTKP) maka akan diperoleh (PKP), dan (PKP) x UU No. 36 Tahun 2008 tarif Pasal 17 Wajib Pajak (WP) untuk PPh Pasal 21 pada PT. Telaga Bakti Persada Ternate. Berikut ini merupakan perhitungan dan pemotongan Wajib Pajak (WP) atas PPh Pasal 21 yang telah dihitung oleh PT. Telaga Bakti Persada Ternate, Sebagai berikut :

1. Untuk kariawan yang memiliki gaji pokok Rp. 6.900.000,- dalam sebulan terdiri 2 orang karyawan A dan C (status sam"a) K/3
Gaji Pokok
Rp. 6.900.000,-
Pend lain
Rp. 2.412.729,-
TJ. makan
Rp. $\quad 150.000,-$ 
TJ. transportasi

TJ.jamsostek

Pendapatan kotor

Pengurangan

Biaya jabatan 5\% x 10.075.949

Iuran pesiun $2 \% 7.550 .000$

$(6.900 .000+150.000+500.000)$

Penghasilan Neto satu bulan

Penghasilan Neto satu tahun

12 × 9.424.949

PTKP Wajib Sendiri Rp. 54.000.000

Status kawin Rp. 4.500 .000

Status Anak 3 Rp. 13.500.000

PTKP satu tahun

Penghasilan Kena Pajak (PKP) Setahun

PPh Pasal 21 satu tahun 5\% x 41.099.308 =

PPh Pasal 21 satu bulan 2.054.969: 12
Rp. 500.000,-
Rp. $113.220,-\quad+$
Rp. 10.075.949
Rp. 500.000,-
Rp. $\quad 151.000,-$
Rp. $651.000,--$
Rp. 9.424.949,-
Rp. 113.099.388,-

2. Untuk karyawan yang memiliki gaji pokok Rp. 4.600 .000 hanya 1 orang karyawan B status K/3

Gaji Pokok

Pend lain/premi

Rp. $\quad 4.600 .000,-$

TJ. Makan

TJ. transportasi

Rp. 2.412.729,-

Rp. 72.000.000,-

Rp. 41.099.308,-

Rp. 2.054.969,-

Rp. 171.247,-

TJ. jamsostek

Rp. $\quad 150.000,-$

Rp. 500.000,-

Pendapatan kotor

Rp. $\quad 113.220,-+$

Rp. 8.075.949,-

Pengurangan

Biaya jabatan 5\% x 8.075.949

Rp. $\quad 403.797,-$

Iuran pesiun $2 \% \quad 5.250 .000$

Rp. 105.000,-

$(4.600 .000+150.000+500.000)$

Penghasilan Sebulan

Rp. $\quad 508.797,-+$

Penghasilan Setahun

12 x 7.567.152

PTKP Wp Sendiri $\quad 54.000 .000,-$

Rp. 7.567.152,-

Rp. $90.805 .824,-$

Anak 3 13.500.000,-

PTKP satu tahun

Rp. 72.000.000,-

PKP satu tahunn

PPh satu tahun 5\% x 18.805.824,-

Rp. 18.805.824,-

PPh satu bulan $940.291: 12$

Rp. $\quad 940.291,-$

Rp. $\quad 78.357,-$

3. Untuk karyawan yang memiliki gaji pokok Rp. 5.700.000 dalam sebulan hanya 1 orang karyawan D status K/0
Gaji Pokok
Rp. $\quad 5.700 .000,-$
Pend lain
Rp. $\quad-$
TJ makan
TJ transportasi
Rp. $\quad 150.000,-$
TJ jamsostek
Rp. 500.000,-
Pendapatan kotor
Rp. $\quad 113.220,-+$
Pengurangan
Biaya jabatan 5\% x 6.463.220
Iuran pesiun $2 \% \quad 6.350 .000$
Rp. 323.161,-
Rp. 127.000,- 


\begin{tabular}{|c|c|c|}
\hline \multicolumn{2}{|c|}{$(5.700 .000+150.000+500.000)$} & $450.161,-+$ \\
\hline \multicolumn{2}{|c|}{ Gaji satu bulan } & Rp. $\quad 6.013 .059,-$ \\
\hline \multicolumn{3}{|l|}{ Gaji satu tahun } \\
\hline \multicolumn{2}{|l|}{$12 \times \quad 6.013 .059$} & Rp. 72.156.708,- \\
\hline \multicolumn{3}{|c|}{ Rp. 54.000.000,- } \\
\hline \multicolumn{3}{|c|}{ kawin $\quad \mathrm{Rp} \quad 4.500 .000$} \\
\hline \multicolumn{2}{|l|}{ PTKP satu tahun } & Rp. $\quad 58.500 .000,-$ \\
\hline \multicolumn{2}{|l|}{ PKP satu tahun } & Rp. $13.656 .708,-$ \\
\hline \multicolumn{2}{|c|}{$\mathrm{PPh}$ satu tahun $5 \% \times .13 .656 .708=$} & Rp. $\quad 682.835,-$ \\
\hline \multicolumn{2}{|c|}{ PPh satu bulan $682.835: 12$} & $56.902,-$ \\
\hline \multicolumn{3}{|c|}{$\begin{array}{l}\text { 4. Untuk karyawan yang memiliki penghasilan atau gaji pokok sebesar Rp. } 5.000 .000 \\
\text { dalam sebulan hanya } 1 \text { orang karyawan E status K/3 }\end{array}$} \\
\hline \multicolumn{2}{|c|}{ Gaji Pokok } & Rp. $\quad 5.000 .000,-$ \\
\hline \multicolumn{2}{|l|}{ Pend lain } & Rp. $\quad 2.412 .729,-$ \\
\hline \multicolumn{2}{|l|}{ TJ makan } & Rp. $\quad 150.000,-$ \\
\hline \multicolumn{2}{|l|}{ TJ transportasi } & $500.000,-$ \\
\hline \multicolumn{2}{|l|}{ TJ jamsostek } & $113.220,-+$ \\
\hline \multicolumn{2}{|l|}{ Pendapatan kotor } & $\begin{array}{ll}\text { Rp. } \quad 8.175 .949,-\end{array}$ \\
\hline \multicolumn{3}{|l|}{ Pengurangan } \\
\hline \multicolumn{2}{|c|}{ Biaya jabatan $5 \%$ x 8.175 .949} & 408.797,- \\
\hline \multicolumn{2}{|c|}{ Iuran pesiun $2 \% \quad 5.650 .000$} & $113.000,-$ \\
\hline \multicolumn{2}{|c|}{$(5.000 .000+150.000+500.000)$} & $521.797,-+$ \\
\hline \multicolumn{2}{|l|}{ Gaji satu bulan } & $7.654 .152,-$ \\
\hline \multicolumn{3}{|l|}{ Gaji satu tahun } \\
\hline \multicolumn{2}{|l|}{$12 \times \quad 7.654 .152$} & Rp. $\quad 91.849 .824$ \\
\hline PTKP Wajibb Sendiri & Rp. 54.000 .000 & \\
\hline kawin & Rp. 4.500 .000 & \\
\hline Anak 3 & Rp. 13.500 .000 & \\
\hline PTKP satu tahun & & Rp. $72.000 .000,-$ \\
\hline PKP satu tahun & & Rp. $19.849 .824,-$ \\
\hline $\mathrm{PPh}$ satu tahun $5 \% \mathrm{x}$. & $19.849 .824=$ & Rp. $\quad 992.491,-$ \\
\hline PPh satu bulan $992.4 \mathrm{C}$ & $1: 12$ & Rp. $\quad 82.707,-$ \\
\hline $\begin{array}{l}\text { 5. Untuk karyawan yang } \\
\text { karyawan F status } \mathrm{K} / 2\end{array}$ & memiliki gaji pokc & 0.000 dalam sebulan hanya 1 orang \\
\hline Gaji Pokok & & Rp. $\quad 6.500 .000,-$ \\
\hline Pend lain & & Rp. - \\
\hline TJ makan & & $150.000,-$ \\
\hline TJ transportasi & & $500.000,-$ \\
\hline TJ jamsostek & & $113.220,-+$ \\
\hline Pendapatan kotor & & Rp. $\quad 7.263 .220,-$ \\
\hline Pengurangan & & \\
\hline Biaya jabatan $5 \% \times 7$ & 913.220 & $363.161,-$ \\
\hline Iuran pesiun $2 \% 7.15$ & 0.000 & $143.000,-$ \\
\hline$(6.500 .000+150.000$ & $+500.000)$ & $506.161,-+$ \\
\hline Gaji satu bulan & & $\begin{array}{ll}\text { Rp. } & 6.757 .059,-\end{array}$ \\
\hline Gaji satu tahun & & \\
\hline $12 \times \quad 6.757 .059$ & & Rp. 81.084.708,- \\
\hline PTKP Wajib Sendiri & Rp. 54.000 .000 & \\
\hline Status kawin & Rp. 4.500 .000 & \\
\hline Status Anak 2 & Rp. 9.000 .000 & \\
\hline
\end{tabular}


PTKP satu tahun

PKP setahun

$\mathrm{PPh}$ satu tahun $5 \% \times 13.584 .708=$

PPh satu bulan 13.584.708: 12 $\begin{array}{lr}\text { Rp. } & 67.500 .000,- \\ \text { Rp. } & 13.584 .708,- \\ \text { Rp. } & 679.235,- \\ \text { Rp. } & 56.603,-\end{array}$

6. untuk karyawan yang memiliki gaji pokok Rp. 4.700 .000 dalam sebulan hanya 1 orang karyawan $\mathrm{G}$ status TK

Gaji Pokok

Pend lain

TJ makan

TJ transportasi

TJ jamsostek

Pendapatan kotor

Pengurangan

Biaya jabatan 5\% x 5.463.220

Iuran pesiun $2 \% 5.350 .000$

$(4.700 .000+150.000+500.000)$

Gaji satu bulan

Gaji satu tahun

12 x 5.083.059

PTKP WP Sendiri Rp. 54.000.000

PTKP satu tahun

PKP satu tahun

Rp. $\quad 4.700 .000,-$

Rp. - $\quad$ -

Rp. $\quad 150.000,-$

Rp. 500.000,-

Rp. $\quad 113.220,-+$

Rp. 5.463.220,-

Rp. 273.161,-

Rp. 107.000,-

Rp. $\quad 380.161,-+$

Rp. 5.083.059,-

Rp. $\quad 60.996 .708,-$

Rp. $\quad 54.000 .000,-$

Rp. 6.996.708,-

Rp. 349.835,-
Rp. 29.153,-
PPh satu bulan $349.83: 12$

7. untuk karyawan yang memiliki penghasilan Rp. 6.000 .000 sebulan 1 orang karyawan $\mathrm{H}$ status TK

Gaji Pokok

Pend lain

TJ makan

TJ transportasi

jamsostek

TJ Pendapatan kotor

Pengurangan

Biaya jabatan 5\% x 6.763.220

Iuran pesiun $2 \% 6.650 .000$

$(6.000 .000+150.000+500.000)$

Penghasilan Neto satu bulan

Penghasilan Neto satu tahun

12 x 6.292.059

PTKP Wajib Sendiri

PTKP satu tahun

PKP setahun

$\mathrm{PPh}$ satu tahun $5 \% \times 21.504 .708=$

PPh satu bulan Rp 1.075.235 : 12
Rp. 6.000.000,-

Rp. - -

Rp. $\quad 150.000,-$

Rp. 500.000,-

Rp. $\quad 113.220,-+$

Rp. 6.763.220,-

Rp. $\quad 338.161,-$

Rp. $\quad 133.000,-$

Rp. $\quad 471.161,-+$

Rp. 6.292.059,-

Rp. 75.504.708,-

Rp. 54.000 .000

Rp. 54.000.000,-

Rp. 21.504.708,-

Rp. 1.075.235,-

Rp. 89.602,-

8. Untuk karyawan yang memiliki gaji pokok Rp. 6.500 .000 dalam sebulan hanya 1 orang karyawan I status K/0
Gaji Pokok
Rp. $\quad 6.500 .000,-$
Pend lain
Rp. -
TJ makan
Rp. $\quad 150.000,-$
TJ transportasi
Rp. 500.000,- 


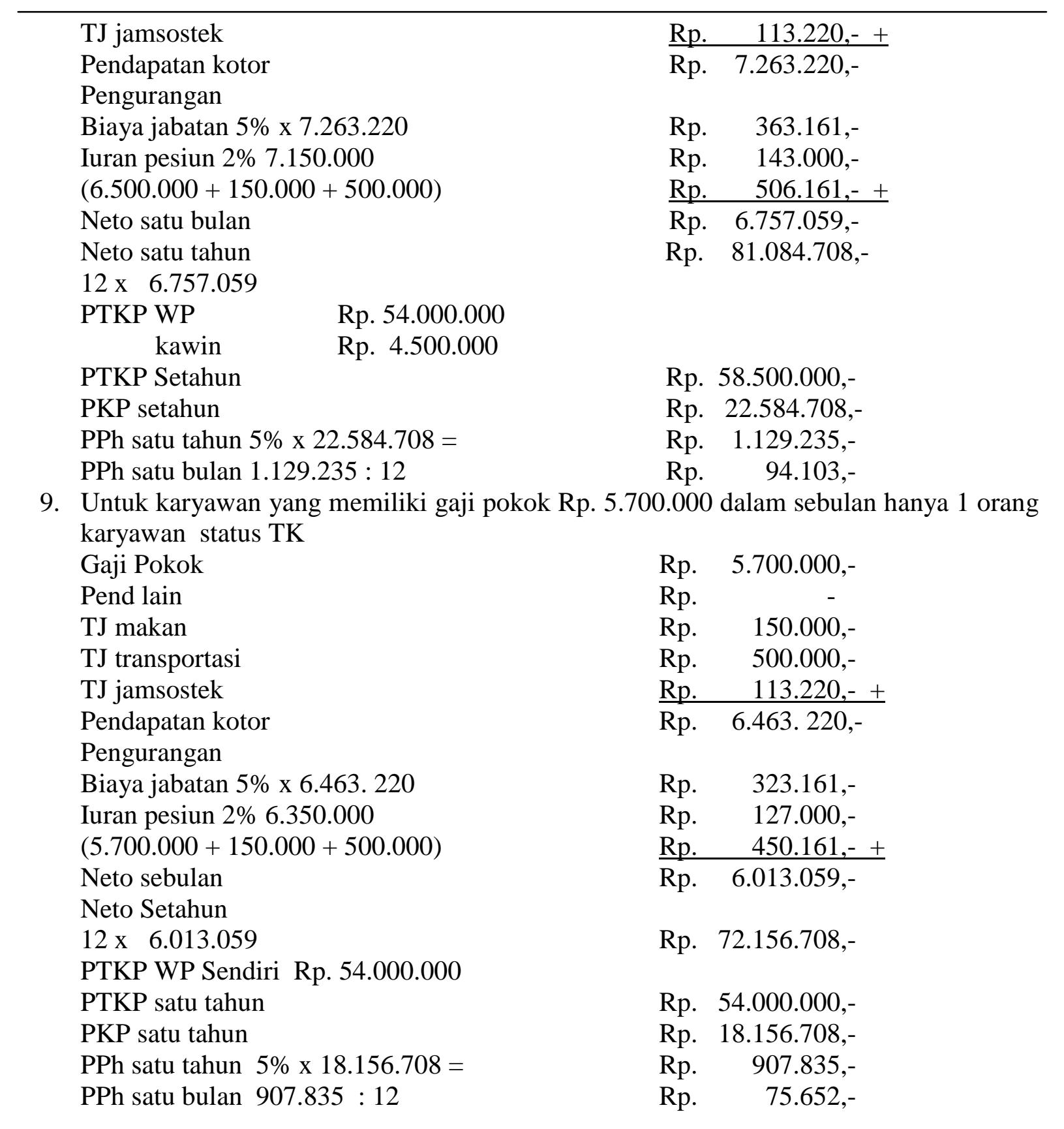




\subsection{Pembahasan}

Pada Tabel 1 Berikut ini merupakan hasil olahan perhitungan PPh Pasal 21 Karyawan tetap pada PT. Telaga Bakti Persada Ternate.

Tabel 1. Hasil Perhitungan dan Pemotongan Pada PT. Telaga Bakti Persada Ternate dan Menurut UU No. 36 Tahun 2008.

\begin{tabular}{|c|c|c|c|c|}
\hline \multirow[b]{2}{*}{ No } & \multirow[b]{2}{*}{ Nama (Status) } & \multicolumn{2}{|c|}{ PPh Pasal 21} & \multirow[b]{2}{*}{ Selisih } \\
\hline & & $\begin{array}{l}\text { Perhitungan } \\
\text { PT. TBP }\end{array}$ & $\begin{array}{c}\text { Hitungan UU No. } 36 \\
\text { Tahun } 2008\end{array}$ & \\
\hline 1. & A $(K / 3)$ & Rp. 171.247 & Rp. 171.247 & Tidak ada \\
\hline 2. & $\mathrm{~B}(\mathrm{~K} / 3)$ & Rp. 78.357 & Rp. 78.357 & Tidak ada \\
\hline 3. & $\mathrm{C}(\mathrm{K} / 3)$ & Rp. 171.247 & Rp. 171.247 & Tidak ada \\
\hline 4. & $\mathrm{D}(\mathrm{K} / 0)$ & Rp. $\quad 56.902$ & Rp. 56.902 & Tidak ada \\
\hline 5. & $\mathrm{E}(\mathrm{K} / 3)$ & Rp. 82.707 & Rp. 82.707 & Tidak ada \\
\hline 6. & $F(K / 2)$ & Rp. 56.603 & Rp. 56.603 & Tidak ada \\
\hline 7. & $\mathrm{G}(\mathrm{TK})$ & Rp. 29.153 & Rp. 29.153 & Tidak ada \\
\hline 8. & $\mathrm{H}(\mathrm{TK})$ & Rp. 89.602 & Rp. 89.602 & Tidak ada \\
\hline 9. & $\mathrm{I}(\mathrm{K} / 0)$ & Rp. 94.103 & Rp. 94.103 & Tidak ada \\
\hline 10. & $\mathrm{~J}(\mathrm{TK})$ & Rp. 75.652 & Rp. 75.652 & Tidak ada \\
\hline
\end{tabular}

Sumber: Data Olahan PT. Telaga Bakti Persada Ternate dan UU No. 30 Tahun 2008 Tentang Pajak Penghasilan (PPh)

Dari hasil Tabel 1 hasil olahan tersebut dapat di simpulan bahwa perhitungan dan pemotongan pajak penghasialan atas gaji karyawan tetap pada PT. Telaga Bakti Persada Ternate, telah dilakukan perhitungan dan pemotongan yang sesuai dengan UU karena tidak adanya selisih.

\section{KESIMPULAN DAN SARAN}

\subsection{Kesimpulan}

Hasil penelitian yang telah di lakukan pada PT. Telaga Bakti Persada Ternate, dapat disimpulkan sebagai berikut : PT. Telaga Bakti Persada Ternate, dalam perhitungan dan pemotongan $\mathrm{PPh}$ Pasal 21 telah sesuai dengan ketentuan peraturan perpajakan UndangUndang No. 36 Tahun 2008 tentang Pajak Penghasilan (PPh).

\subsection{Saran}

Saran dari hasil penelitian, maka sarannya adalah :

1. Pajak merupakan penerimaan terbesar bagi negara, oleh karena itu diharapkan kepada PT. Telaga Bakti Persada Ternate agar melakukan perhitungan dan pemotongan sesuai dengan UU yang berlaku saat ini.

2. Perusahaan agar selalu mengikuti perkembangan terbaru mengenai UU Pajak Penghasilan Pasal 21 agar proses pemotongan tetap sesuai dengan UU yang belaku.

\section{DAFTAR PUSTAKA}

Agoes Sukrisno \& Estralita Trisnawati, 2013. Akuntansi Perpajakan. Salemba Empat. Jakarta.

Angelina Friska Makabimbang, 2013. Analisis Perhitungan, Pembayaran dan Pelaporan Pph Pasal 21 Pada Dinas Pedidikan Kecamatan Tuminting. Jurnal Riset Ekonomi, Manajemen, Bisnis dan Akuntansi. Fakultas Ekonomi Universitas Samratulangi Manado. Vol 1 No. 04 (2013). 
Chairil Pohan, 2013 Manajemen Perpajakan, Edisi Revisi. PT. Gramedia Pustaka Utama. Jakarta

Djoko Muijoo, 2008 Tax Planning. Edisi 1. Andi. Yogyakarta.

Harnanto. 2013. Perencanaan Pajak. Cetakan Pertama. BPFE. Yogyakarta

Hans Kartikahadi, dkk. (2016:3) Akuntansi Keuangan berdasarkan SAK berbasis IFRS. Salemba. Jakarta

Irsan Lubis, 2014. Mahir Akuntasi Pajak Terapan. Edisi 1. Andi. Yogyakarta.

Jeane Susan. 2013. Analisis Perhitungan Pajak Pengahasilan Pasal 21 Pada PT. Megasurya. Jurnal Riset Ekonomi, Manajemen, Bisnis dan Akuntansi. Fakultas Ekonomi Universitas Samratulangi Manado. Vol 1 No. 04 (2013).

Kasmir. 2012. Analisis Laporan Keuangan. PT. Raja Grafindo Persada. Jakarta

Leo Agung Dwi Pangestu, 2017. Perpajakan Brevet A\&B. Cetakan Pertama. Camp. Yogyakarta.

Mardiasmo, 2015. Perpajakan Edisi Revisi. Andi. Yogyakarta.

Pemeritah Republik Indonesia. 2008. Undang-Undang No. 36. Tahun 2008 Tentang Pajak Penghasilan. Jakarta.

Rochmat soemitro SH, 2011. Perpajakan Edisi Revisi. Andi. Yogyakarta. 